\title{
Methods for detection of hepatitis B surface antigen in paraffin sections of liver: a guideline for their use
}

\author{
E. SUMITHRAN
}

From the Department of Pathology, Medical Faculty, University of Malaya, Kuala Lumpur, Malaysia

SUMMARY Methods for the localisation of hepatitis B surface antigen $\left(\mathrm{HB}_{\mathbf{s}} \mathrm{Ag}\right)$ in paraffin sections of the liver include the detection of ground-glass hepatocytes and the use of Shikata's orcein stain, $\dot{\sigma}^{\circ}$ and of immunoperoxidase and immunofluorescent techniques. A comparative study of the different ir methods on 20 livers shows the orcein stain to be the method of choice for routine use. The Shikata $\vec{\circ}$ stain is not only specific but is relatively inexpensive, easily performed, and stains out distinct cytoplasmic inclusions even in stored formalin-fixed livers, old paraffin blocks, and autolysed livers. Since $\mathrm{HB}_{\mathrm{s}} \mathrm{Ag}$ is irregularly distributed in the liver, adequate sampling is necessary to prevent false $\vec{z}$ negatives; when sufficient tissue is available at least five blocks should be examined before a case is labelled as $\mathrm{HB}_{\mathrm{s}} \mathrm{Ag}$-negative.

In recent years there has been a growing interest in the detection of hepatitis $\mathrm{B}$ surface antigen $\left(\mathrm{HB}_{\mathrm{s}} \mathrm{Ag}\right)$ in paraffin-embedded liver tissue. Methods for the localisation of $\mathrm{HB}_{\mathrm{S}} \mathrm{Ag}$ in paraffin sections of the liver include the detection of ground-glass hepatocytes in haematoxylin and eosin preparations (Hadziyannis et al., 1973) and the use of Shikata's orcein stain (Shikata et al., 1974) and of immunoperoxidase (Burns, 1975) and immunofluorescent (Akeyama et al., 1972) techniques. These methods have been invaluable as research tools in the retrospective detection of $\mathrm{HB}_{\mathrm{s}} \mathrm{Ag}$ in stored formalin-fixed livers and in old paraffin blocks containing liver tissue. They are also of value in clinical diagnosis. The specificity and reliability of the methods have previously been compared (Nayak and Sachdeva, 1975; Portmann et al., 1976) but few guidelines for their use are available.

We have used the above methods in retrospective studies on liver tissue from Malaysian Aborigines (Orang Asli) who have a very high incidence of primary hepatocellular carcinoma (Sumithran and Prathap, 1976) and have found attributes and deficiencies in all the methods. A major problem is that $\mathrm{HB}_{8} \mathrm{Ag}$ may be sparsely distributed in the liver and fail to be detected unless an adequate number of blocks are examined. How many blocks constitute an 'adequate number' has not been established. In view of the great use being made of these methods for the detection of $\mathrm{HB}_{\mathbf{8}} \mathrm{Ag}$, there exists a need for

Received for publication 4 October 1976 proper guidelines to their use. This paper, the result of a comparative study of the different methods, outlines suggestions for their use.

\section{Material and methods}

Twenty formalin-fixed cirrhotic livers from necropsied Orang Asli subjects were used in the study. Ten of the livers had associated primary hepatocellular carcinomas. Two livers, one of which contained a용 liver cancer, were badly autolysed: cell outlines were indistinct and nuclei were lost. The livers had been 3 . preserved in formalin for from one to 10 years. Paraffin blocks from all the livers made at the time of necropsy were available. The number of such blocks 응 available from each liver ranged from two to five? (average three).

Serial sections, $3 \mu \mathrm{m}$, were cut, and four consecutive sections from a ribbon were picked up on glass $\sigma$ slides numbered 1 to 4 . Slide 1 was stained by haematoxylin and eosin, slide 2 by orcein, slide 3 N by the immunoperoxidase method, and slide 4 by the immunofluorescent method.

From each formalin-fixed liver 10 fresh squar $\in$ pieces of tissue were randomly taken from different areas. Each piece, measuring $1.5 \times 1.5 \times 0.3 \mathrm{~cm}_{\square}$ in size, was blocked in paraffin. The 10 blocks from each liver were randomly tagged $A$ to J. Serial迎 sections, $3 \mu \mathrm{m}$, were cut from each block, and four $\frac{}{\mathbb{D}}$ consecutive sections from a ribbon were picked up on $\frac{\mathrm{Q}}{\sigma}$ glass slides numbered 1 to 4 . As before, the slides? were stained by the four methods. 
Orcein staining was carried out using the method of Shikata et al. (1974). The deparaffinised sections were oxidised in a $0.15 \%$ solution of potassium permanganate and sulphuric acid $\left(0 \cdot 15 \mathrm{~g} \mathrm{KMnO}_{4}+\right.$ $100 \mathrm{ml}$ distilled water $+0.015 \mathrm{ml}$ conc. $\mathrm{H}_{2} \mathrm{SO}_{4}$ ) for five minutes. (Oxidation gives good contrast in the final product.) The sections were then decolourised in $2 \%$ oxalic acid (10 minutes), washed in water, and placed in a $1 \%$ solution of orcein $(\mathrm{BDH})$ in $70 \%$ alcohol at $\mathrm{pH} 1-2(1 \mathrm{~g}$ orcein $+100 \mathrm{ml} 70 \%$ alcohol $+2 \mathrm{ml}$ conc. $\mathrm{HCl}$ ) for four hours. The sections were finally differentiated in absolute alcohol, dehydrated in xylene, and mounted. Orcein-positive cells stain dark brown against a background of very light brown negative cells.

Immunoperoxidase staining was carried out by the indirect sandwich technique after endogenous peroxidase had been blocked by immersing the sections in methanol containing $0.3 \%$ hydrogen peroxide. Specific rabbit antiserum against $\mathrm{HB}_{\mathrm{s}} \mathrm{Ag}$ (anti-Au/SH serum from Behringwerke AG, Germany) and a swine antirabbit immunoglobulin conjugated with horseradish peroxidase (obtained from Dakopatts AS, Denmark) were used. The tissue-bound peroxidase-conjugated antibody was stained with diaminobenzidine (DAB from BDH Chemicals, England).

Immunofluorescent staining was also carried out by an indirect technique using the same rabbit antiserum against $\mathbf{H B}_{\mathbf{s}} \mathrm{Ag}$ as above and sheep antirabbit immunoglobulin tagged with fluorescein (Wellcome Research Laboratories, England).

\section{Results}

All the livers were found to contain $\mathrm{HB}_{\mathrm{s}} \mathrm{Ag}$ on examination of multiple blocks (Table 1). There was little to choose from between the orcein stain and the immunoperoxidase method; each method distinctly stained out the positive areas. The $\mathrm{HB}_{\mathrm{B}} \mathrm{Ag}$ positive cells, when abundantly present, were readily appreciated by the immunofluorescent method, but when $\mathrm{HB}_{\mathrm{S}} \mathrm{Ag}$ was sparsely present the background

Table 1 Number of livers showing ground glass, orcein, peroxidase, and immunofluorescent positive hepatocytes in relation to type of block examined

\begin{tabular}{|c|c|c|c|c|}
\hline \multirow{2}{*}{$\begin{array}{l}\text { Type of } \\
\text { block } \\
\text { examined }\end{array}$} & \multicolumn{4}{|c|}{ Number of livers (total 20) } \\
\hline & $\begin{array}{l}\text { Ground- } \\
\text { glass }\end{array}$ & Orcein & Peroxidase & $\begin{array}{l}\text { Immuno- } \\
\text { fluorescent }\end{array}$ \\
\hline $\begin{array}{l}\text { Stored } \\
\text { paraffin } \\
\text { (av. } 3 \text { per liver) }\end{array}$ & r) 9 & 15 & 15 & 15 \\
\hline $\begin{array}{l}\text { Fresh } \\
\text { (10 per liver) }\end{array}$ & 12 & 20 & 20 & 20 \\
\hline
\end{tabular}

fluorescence made the few positive cells difficult to detect.

As previously described (Nayak and Sachdeva, 1975), the material which stained positively with the empirical orcein stain showed complete identity with that stained by the immunospecific methods. Localisation both within focal areas and in individual cells matched extremely well with those seen in the immunoperoxidase (Figs 1 and 2) and immunofluorescent preparations.

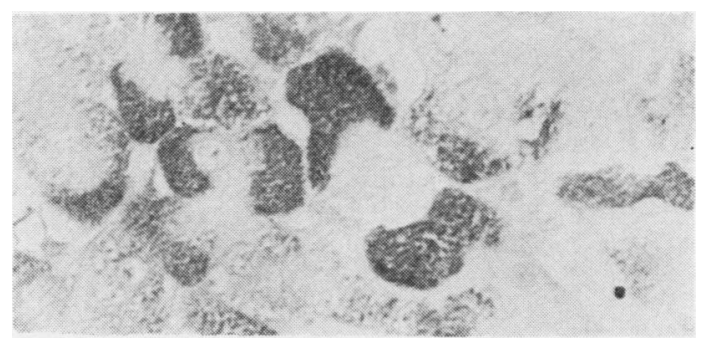

Fig. 1 Orcein-positive inclusions in hepatocytes $(\times 450)$

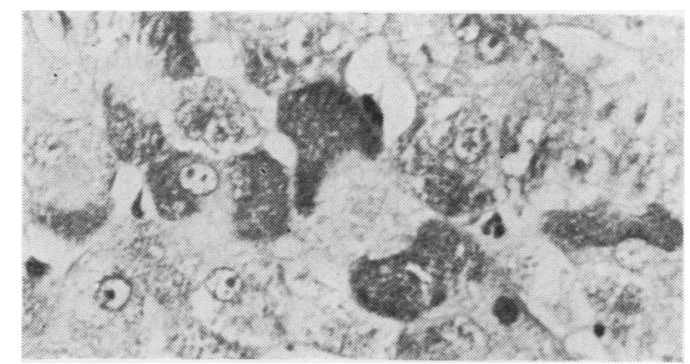

Fig. 2 Immunoperoxidase-positive inclusions in section contiguous to that illustrated in Fig. $1(\times 450)$

In less than one-half of the livers was $\mathrm{HB}_{\mathbf{s}} \mathrm{Ag}$ so abundant as to be detected on examination of a single block. In some livers $\mathrm{HB}_{\mathrm{s}} \mathrm{Ag}$ was confined to parts of small nodules. The number of positive cases increased as more blocks were examined (Table 2). On examination of one block per liver, only $45 \%$ of the livers were found to be positive. On examination of five blocks $95 \%$ of the livers were found to

Table 2 Number of livers with $\mathrm{HB}_{8}$ Ag-positive hepatocytes in relation to number of blocks examined

\begin{tabular}{lll}
\hline $\begin{array}{l}\text { No. of blocks } \\
\text { examined per liver }\end{array}$ & $\begin{array}{l}\text { No. of livers } \\
\text { positive }(\text { total 20) }\end{array}$ & $\begin{array}{l}\text { \%oflivers } \\
\text { positive }\end{array}$ \\
\hline 1 & 9 & 45 \\
2 & 11 & 55 \\
3 & 16 & 80 \\
4 & 17 & 85 \\
5 & 19 & 95 \\
6 & 19 & 95 \\
7 & 20 & 100 \\
\hline
\end{tabular}


contain $\mathrm{HB}_{\mathrm{s}} \mathrm{Ag}$. The difference in the number of positive cases between the fresh blocks and stored blocks (Table 1) was probably due entirely to the greater number of the former.

The two extremely autolysed livers surprisingly contained material which stained strongly positive with orcein and the immunospecific methods (Figs 3 and 4).

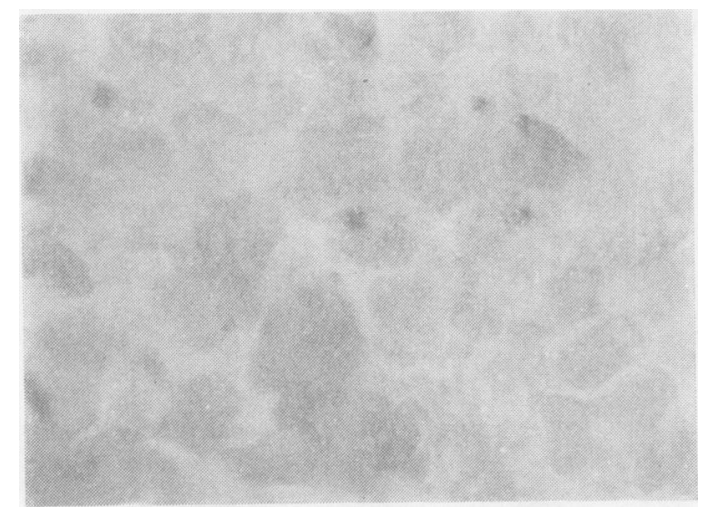

Fig. 3 Autolysed hepatocytes (Haematoxylin and eosin $\times 500$ )

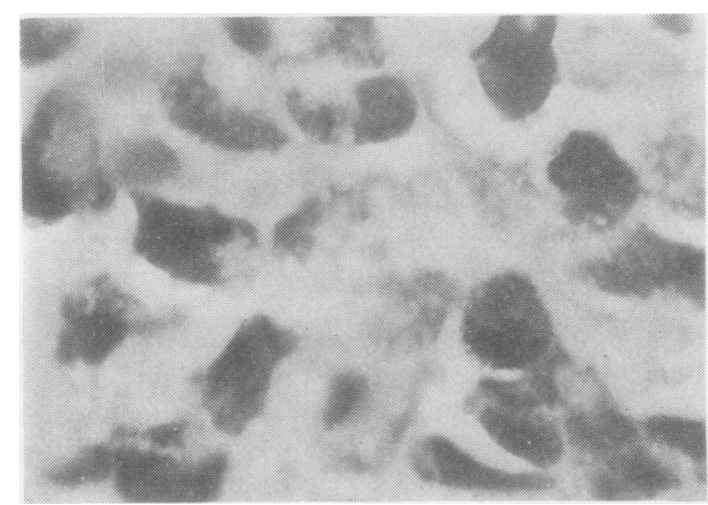

Fig. 4 Orcein-positive inclusions in autolysed hepatocytes $(\times 500)$

Although the orcein and immunologically stained material was present mainly in the noncancerous parenchyma of the livers with hepatocellular carcinoma, in two such livers small focal areas of tumour contained orcein, immunoperoxidase, and immunofluorescent-positive cytoplasmic inclusions, as has previously been described (Nayak and Sachdeva, 1975).

Typical ground-glass hepatocytes, as described by Hadziyannis et al. (1973), were present in only small numbers in $60 \%$ of the livers. The majority of hepatocytes with $\mathbf{H B}_{\mathbf{s}} \mathrm{Ag}$-positive inclusions did not have a typical ground-glass appearance.

\section{Discussion}

$\mathrm{HB}_{\mathrm{s}} \mathrm{Ag}$ may be detected in hepatocytes using immunospecific methods or by the empirical orcein stain. There is complete identity between the material which stains positive with orcein and that stained by immunofluorescent and immunoperoxidase methods. Interference by background fluorescence decreases the value of the immunofluorescent technique, especially when $\mathrm{HB}_{\mathbf{s}} \mathrm{Ag}$ is sparsely present, but both the orcein and immunoperoxidase methods stain out the inclusions distinctly. Since the products of the latter two procedures are equally satisfactory, the very much lower cost of the orcein method and the relative simplicity of its technique make it the method of choice for the routine detection of $\mathrm{HB}_{\mathrm{s}} \mathrm{Ag}$ in fixed liver tissue.

The immunoperoxidase and immunofluorescent methods may, however, be useful for further studies on livers containing $\mathbf{H B}_{\mathbf{s}} \mathbf{A g}$. Nuclear staining has never been observed with orcein, and should the demonstration of hepatitis $B$ core antigen become an important research or diagnostic tool, then immunospecific methods may have to be used. Ray et al. (1976) have found a number of different staining patterns by immunofluorescence in chronic hepatitis and in acute hepatitis, which may prove to be helpful in the histological diagnosis of different types of $\mathrm{HB}_{\mathrm{S}} \mathrm{Ag}$-positive hepatitis.

$\mathrm{HB}_{\mathrm{s}} \mathrm{Ag}$ appears to be rather stable; neither formalin-fixation for several years nor paraffinembedding seems to inactivate its antigenic determinants. Material used in this study has been in formalin or has been paraffin-embedded for up to 10 years. Shikata (1974) has stained specimens from patients with cirrhosis that have been in the files for as long as 50 years. Moreover, $\mathrm{HB}_{\mathrm{s}} \mathrm{Ag}$ is readily detected even in badly autolysed livers.

The ground-glass hepatocyte is little more than a useful diagnostic hint for the presence of $\mathrm{HB}_{\mathrm{s}} \mathrm{Ag}$. It may occur in other conditions, such as druginduced liver injury, cholestasis, and alcoholic hepatitis (Popper, 1975). These cells were present in small numbers in only $60 \%$ of livers carrying the hepatitis B surface antigen. The majority of hepatocytes with $\mathrm{HB}_{\mathbf{s}} \mathrm{Ag}$-positive inclusions did not have a typical ground-glass appearance. Nayak and Sachdeva (1975), who also based their work on necropsy material, were unable to identify ground-glass hepatocytes in liver tissue containing orcein, immunoperoxidase, and immunofluorescent-positive hepatocytes. This observation differs from the findings of Portmann et al. (1976), who found 
ground-glass hepatocytes in all the needle liver biopsies which were positive for $\mathrm{HB}_{\mathrm{s}} \mathrm{Ag}$ by immunofluorescence or orcein methods; the ground-glass cells corresponded well with those containing $\mathrm{HB}_{\mathrm{s}} \mathrm{Ag}$. Their study, however, did not include postmortem material. The ground-glass appearance is thought to be due to an increase in the smooth endoplasmic reticulum of the affected hepatocytes. Since cell organelles autolyse fairly rapidly after death, it is possible that $\mathrm{HB}_{\mathbf{s}} \mathrm{Ag}$-positive hepatocytes may lose their ground-glass appearance within a few hours of death. This may be the explanation for the paucity of ground-glass hepatocytes in necropsy material.

Owing to the irregular distribution of $\mathrm{HB}_{\mathrm{s}} \mathrm{Ag}$ in the liver, adequate sampling of tissue is required before a case is labelled as antigen-negative. When limited material is available, as in needle liver biopsies, the number of false negatives due to sampling error is likely to be very great. Examination of only one block from each liver resulted in more than $50 \%$ of false negatives. When a large amount of tissue is available, it is imperative that multiple blocks be examined before a case is labelled as antigen-negative. Examination of five $1.5 \mathrm{~cm}$ square blocks from each liver resulted in failure in detection of $\mathrm{HB}_{\mathrm{g}} \mathrm{Ag}$ in only one of the 20 livers.

In conclusion, for the routine detection of $\mathrm{HB}_{\mathrm{s}} \mathrm{Ag}$ in paraffin sections of the liver, Shikata's orcein stain is the method of choice. It is not only specific but is relatively inexpensive and easily performed, and stains out distinct cytoplasmic inclusions even in stored formalin-fixed livers and old paraffin blocks. Autolysis does not invalidate orcein staining. Adequate sampling is necessary to prevent false negatives. When large amounts of liver tissue are available, at least five blocks should be examined.

\section{References}

Akeyama, T., Kamada, T., Koizumi, T., and Abe, $\mathbf{H}$. (1972). The localization of the Australia antigen in the liver by immunofluorescence. J. clin. Path., 25, 1071-1074.

Burns, J. (1975). Immunoperoxidase localization of hepatitis B antigen (HB) in formalin-paraffin processed liver tissue. Histochemistry, 44, 133-135.

Hadziyannis, S., Gerber, M. A., Vissoulis, C., and Popper, H. (1973). Cytoplasmic hepatitis B antigen in 'ground-glass' hepatocytes of carriers. Arch. Path., 96, 327-330.

Nayak, N. C. and Sachdeva, R. (1975). Localization of hepatitis $\mathbf{B}$ surface antigen in conventional paraffin sections of the liver. Amer. J. Path., 81, 479-492.

Popper, H. (1975). The ground glass hepatocyte as a diagnostic hint. Hum. Path., 6, 517-520.

Portmann, B., Galbraith, R. M., Eddleston, A. L. W. F., Zuckerman, A. J., and Williams, R. (1976). Detection of $\mathrm{HB}_{\mathbf{s}} \mathrm{Ag}$ in fixed liver tissue-use of a modified immunofluorescent technique and comparison with histochemical methods. Gut, 17, 1-9.

Ray, M. B., Desmet, V. J., Fevery, J., De Groote, J., Bradbourne, A. F., and Desmyter, J. (1976). Distribution patterns of hepatitis $B$ surface antigen $\left(\mathrm{HB}_{\mathrm{B}} \mathrm{Ag}\right)$ in the liver of hepatitis patients. J. clin. Path., 29, 94-100.

Shikata, T. (1974). Australia antigen detected in the liver tissues which were obtained half a century ago. Hepatitis Scientific Memorandum, H655.

Shikata, T., Uzawa, T., Yoshiwara, N., Akatsuka, T., and Yamazaki, S. (1974). Staining methods of Australia antigen in paraffin section: detection of cytoplasmic inclusion bodies. Jap. J. exp. Med., 44, 25-36.

Sumithran, E. and Prathap, K. (1976). Hepatocellular carcinoma in the Malaysian Orang Asli. Cancer (Philad.), 37, 2263-2266. 